Proceeding

\title{
Pregnancy and breastfeeding after treated breast cancer: inquest to health professionals in agadir
}

Keywords: pregnancy, breastfeeding, treated breast cancer, prognosis, knowledge

\section{Objective and aims}

In Morocco, breast cancer is the first cancer in women and its incidence is progressively increasing in young patients. Furthermore, the declines in age of first pregnancy generate, probably in future years a growing number of breast cancer cases in premenopausal women before completing their maternity project. The health professionals will find themselves increasingly faced with a situation of planning the pregnancy in a young patient with a breast cancer history. The objective of our study is to examine the health professionals' knowing on pregnancy and the practice of breastfeeding after treated breast cancer.

\section{Result}

Forty questionnaires were completed by health professionals exercising at Agadir hospital. The analysis of this questionnaires showed that $60 \%$ of professionals interviewed have met women having pregnant after breast cancer treatment. Nonetheless, $67 \%$ do not have clear information on the subject and the possibility of pregnancy and lactation after breast cancer and their potential risks. Some physio-pathological, psychological, cultural and social factors may influence the initiation of a pregnancy and breastfeeding in a woman of reproductive age who has been treated for breast cancer. Moreover, several women do not contemplate a pregnancy after a breast cancer and this is due to repeatedly non-justified reasons coming from their health professionals.

\section{Conclusion}

Due to the development of new therapeutic treatments in recent years, a pregnancy can be planned for the young women after breast cancer. No data report the deleterious effect of pregnancy on breast cancer prognosis, neither an additional risk of malformation in pregnancy after treatment for breast cancer. However, it is recommended to respect a caution period. It is suggested a delay within two to three years for patients with a good prognosis cancer and a delay of five years for patients with a bad prognosis in breast cancer. For the breastfeeding impact after breast cancer, nowadays,
Volume 7 Issue 5 - 2017

\author{
Smail Chadli, ${ }^{1,2}$ Naima Taqarort, ${ }^{3}$ Said \\ Oulkheir' \\ 'Higher Institute of Nursing Professions and Health Techniques, \\ Morocco \\ ${ }^{2}$ Laboratory of Cellular Biology and Molecular Genetics, Ibn \\ Zohr University, Morocco \\ ${ }^{3}$ Polydisciplinary faculty of Taroudant, Ibn Zohr University, \\ Morocco
}

Correspondence: Smail CHADLI, Higher Institute of Nursing Professions and Health Techniques, ISPITS- Agadir, Morocco, Tel 212663 II 099, Fax 212528843987 ,

Emailschadli@gmail.com

Received: February 10, 2017 | Published: March 03, 2017

there is no evidence on the risk of a second breast cancer or risk of recurrence in the conserved breast. The health professionals has role to provide answers to the questions that may be encountered in this type of highly difficult situation. They must have clear information about post-chemotherapy premature ovarian failure, fertility preservation opportunities and the optimal time between cancer and future pregnancy or the consequences of this disease on the pregnancy course and breastfeeding chances and its prognostic impact.

\section{Funding}

None.

\section{Acknowledgements}

None.

\section{Conflicts of interests}

The authors declare that there is no conflict of interest. 